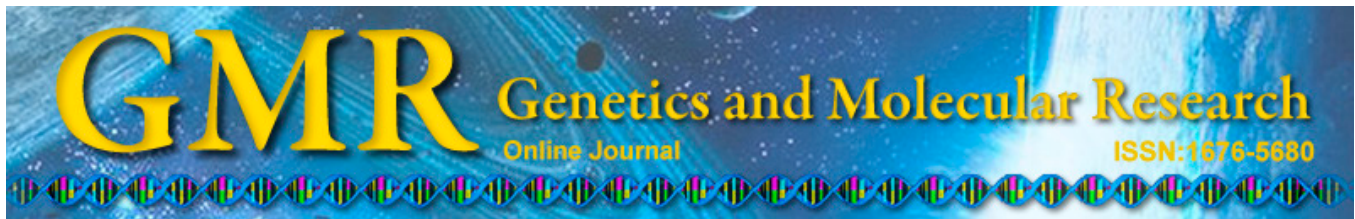

\title{
Protective effect of penehyclidine hydrochloride on lipopolysaccharide-induced acute kidney injury in rat
}

H.J. Ca0 ${ }^{1,2}$, D.M. Yu ${ }^{2}$, T.Z. Zhang ${ }^{2}, \mathrm{~J} . \mathrm{Zhou}^{2}, \mathrm{~K}$ Y. Chen ${ }^{2}, \mathrm{~J} \mathrm{Ge}^{3}$ and L. Pei

${ }^{1}$ Department of Anesthesiology,

First Affiliated Hospital of China Medical University, Shenyang,

Liaoning Province, China

${ }^{2}$ Department of Anesthesiology,

The General Hospital of Shenyang Military Region, Shenyang,

Liaoning Province, China

${ }^{3}$ Department of Gynecology and Obstetrics,

The General Hospital of Shenyang Military Region, Shenyang,

Liaoning Province, China

Corresponding author: L. Pei

E-mail: lingpei49@vip.sina.com

Genet. Mol. Res. 14 (3): 9334-9342 (2015)

Received January 8, 2015

Accepted April 17, 2015

Published August 10, 2015

DOI http://dx.doi.org/10.4238/2015.August.10.14

ABSTRACT. We aimed to observe the effect of penehyclidine hydrochloride (PHC) on lipopolysaccharide (LPS)-induced acute kidney injury in rats and expression of tight junction proteins ZO-1 and occludin. Adult male Sprague-Dawley (SD) rats were divided randomly $(\mathrm{N}=10)$ into control group (C), LPS group (LPS), low-dose PHC group (L-PHC), and high-dose PHC group (H-PHC). All rats, except C group, received a vena caudalis injection of $5.0 \mathrm{mg} / \mathrm{kg}$ LPS; after $30 \mathrm{~min}$, rats in L-PHC and H-PHC groups received a vena caudalis injection of 0.3 and $0.9 \mathrm{mg} / \mathrm{kg}$ PHC. After $24 \mathrm{~h}$, tumor necrosis factor (TNF)- $\alpha$, interleukin (IL)- $1 \beta$, serum creatinine (Scr), and blood urea nitrogen (BUN) were detected. Histopathological changes and expression of $\mathrm{ZO}-1$ and 
occludin were observed in renal tissues. Versus levels of TNF- $\alpha$ (38.5 $\pm 9.0)$, IL-1 $(46.3 \pm 12.7)$, Scr (37.2 \pm 9.3$)$, and BUN $(6.5 \pm 1.1)$ in control group, those in LPS group, TNF- $\alpha(159.0 \pm 21.3)$, IL-1 $\beta$ (130.8 $\pm 18.7)$, Scr (98.5 \pm 18.2$)$, and BUN (12.8 \pm 1.8$)$, increased obviously $(\mathrm{P}<0.05)$, with significantly structural changes and decreases of ZO-1 and occludin. However, TNF- $\alpha$ (111.3 \pm 11.6$),$ IL-1 $\beta$ (78.4 \pm 14.3$)$, Scr $(51.3 \pm 12.5)$, BUN $(8.1 \pm 1.2)$ in H-PHC group, and TNF- $\alpha(120.8 \pm$ 14.3), IL-1 $\beta$ (92.5 \pm 19.0$)$, Scr (56.7 \pm 14.7$),$ BUN $(9.7 \pm 1.6)$ in L-PHC group were obviously decreased $(\mathrm{P}<0.05)$. PHC has protective effects on acute kidney injury in sepsis, including abatement of renal tissue inflammation and functional improvement, potentially by upregulating ZO-1 and occludin.

Key words: Penehyclidine hydrochloride; Acute kidney injury; Lipopolysaccharide

\section{INTRODUCTION}

Sepsis is the systemic inflammatory response induced by infection and one of the most common causes of acute kidney injury (AKI) (Bagshaw et al., 2007). With AKI being one of the independent risk factors for poor prognosis, the mortality of sepsis patients with AKI is higher than those without AKI (Korkeila et al., 2000; Metnitz et al., 2002; Bagshaw et al., 2005; Uchino et al., 2005). Therefore, protection of renal function should help reduce mortality and improve the prognosis in patients with sepsis. However, there are very limited means for the prevention and treatment of sepsis-induced AKI (Ricci et al., 2011). Penehyclidine hydrochloride (PHC) is a type of selective Belladonna drug that originated in China. Recent studies have focused on its effect of improving microcirculation, reducing the permeability of the capillary wall, reducing lysosomal release, and suppressing the LPS-induced aggregation of polymorphonuclear leukocytes in the lung and further lipid peroxidation damage (Shen et al., 2008; Li et al., 2011; Zhan et al., 2011, 2015). However, its role in septic AKI is seldom studied. In vivo studies and cell culture models suggest that tight junction proteins, which regulate renal tubular cell permeability in various tissues, would change in case of ischemic injury, free radical damage, and ATP depletion, and their expression also would change (Eadon et al., 2012). In our study, we applied PHC at clinically relevant concentrations to rats with endotoxemia to observe its effect on renal function, inflammatory response, and tight junction protein expression.

\section{MATERIAL AND METHODS}

\section{Animals}

Forty healthy, male Sprague-Dawley rats of clean grade (aged four to six months, weighing 180-220 g) were purchased from the Experimental Animal Center of the General Hospital of Shenyang Military Region, Shenyang, China. Animal experiments were approved by the Animal Ethics Committee of the General Hospital of Shenyang Military Region and were conducted in strict accordance with the Animal Experiments Guide of the General Hospital of Shenyang Military Region. All 40 rats were divided randomly into four groups with 
10 rats in each group: control group (C group), LPS model group (LPS group), PHC low-dose group (L-PHC group), and PHC high-dose group (H-PHC group). Rats in the control group received an injection of $5.0 \mathrm{mg} / \mathrm{kg}$ normal saline (NS) via the tail vein, while rats in all the other groups received an equivalent amount of LPS (from Escherichia coli 055:B5, Sigma Company). After 30 min, rats were administered NS or PHC (Lisite Pharmacology Co. Chengdou, China, No. 080301) via the tail vein based on their assigned groups. The dosing volume was 3 $\mathrm{mL} / \mathrm{kg}$, and the dosage for rats in the L-PHC and the H-PHC groups were 0.3 and $0.9 \mathrm{mg} / \mathrm{kg}$, respectively. Then, $24 \mathrm{~h}$ after LPS injection, animals were sacrificed with an intraperitoneal injection of $10 \%$ chloral hydrate at $350 \mathrm{mg} / \mathrm{kg}$. Blood $(3 \mathrm{~mL})$ was drawn from the femoral vein of each rat, and the upper serum was collected after 15 min of centrifugation at $2500 \mathrm{~g}$.

\section{Detection of indexes}

An automatic biochemical analyzer (Hitachi, Tokyo, Japan) was used for the analysis of serum creatinine (Scr) and blood urea nitrogen (BUN).

Blood serum tumor necrosis factor (TNF)- $\alpha$ and interleukin (IL)-1 $\beta$ were detected by enzyme-linked immunosorbent assay (ELISA) (Elabscience Biotechnology, Wuhan, China). A standard curve was established according to kit instructions, and the concentrations $(\mathrm{pg} / \mathrm{mL})$ of TNF- $\alpha$ and IL- $1 \beta$ in the test specimens were calculated according to the standard curve.

The upper part of the right kidney was fixed in $10 \%$ formaldehyde, dehydrated, impregnated in wax, embedded, and sliced for hematoxylin and eosin (H\&E) staining, before observation under an optical microscope at 200X magnification. The lower half of the right kidney was cut into tissue pieces of $1 \times 1 \times 1 \mathrm{~mm}$ in size, fixed in $2.5 \%$ glutaraldehyde and $1 \%$ osmic acid, and then dehydrated with ethanol, embedded with epoxy, and sectioned to observe glomerular and tubular ultrastructure under transmission electron microscope.

After the left kidney of the rat was collected, tissue lysates were applied for the decomposition of renal tissue, and after centrifugation of the homogenate, the supernatant was collected for the determination of total protein content before it was aliquoted and preserved at $-80^{\circ} \mathrm{C}$. After SDS-polyacrylamide gel electrophoresis (SDS-PAGE), the proteins were transferred to a nitrocellulose membrane and incubated overnight with rabbit anti-rat ZO-1 and rabbit anti-rat occludin antibodies (Zymed Laboratories, South San Francisco, CA, USA). Then, secondary antibodies labeled with horseradish peroxidase were added, and the membranes were incubated at room temperature for another hour. The enhanced chemiluminescence method was used for visualization and imaging. $\beta$-actin was chosen as the internal reference, and a transmission scanner was used for scanning. The QuantiScan gel image scanning software (Biosoft, Cambridge, UK) was applied for measuring the optical density (OD) values of the electrophoretic bands. Then, the OD ratio of ZO-1 or occludin to the internal reference was used to reflect the expression levels of these two proteins.

\section{Statistical analysis}

All quantitative data are reported as means \pm standard deviation and were analyzed using SPSS for Windows 13.0 (Chicago, IL, USA). One-way ANOVA and the Student-Newman-Keuls post hoc test were used to determine the significance of differences among various groups. $\mathrm{P}<0.05$ was considered to be statistically significant. 


\section{RESULTS}

\section{Comparison of Scr and BUN levels among various groups}

A significant increase of both Scr and BUN in the LPS group compared with the C group $(\mathrm{P}<0.05)$ was observed whereas Scr and BUN significantly decreased in both L-PHC and H-PHC groups compared with the LPS group $(\mathrm{P}<0.05)$ (Table 1).

\section{Table 1. Changes of Scr and BUN in each group (means $\pm \mathrm{SD}, \mathrm{N}=10$ ).}

\begin{tabular}{llc}
\hline Group & Scr $\left(\mu_{\mathrm{M}}\right)$ & BUN $(\mathrm{mM})$ \\
\hline C & $37.2 \pm 9.3$ & $6.5 \pm 1.1$ \\
LPS & $98.5 \pm 18.2^{*}$ & $12.8 \pm 1.8^{*}$ \\
L-PHC & $56.7 \pm 14.7^{\Delta}$ & $9.7 \pm 1.6^{\Delta}$ \\
H-PHC & $51.3 \pm 12.5^{\Delta}$ & $8.1 \pm 1.2^{\Delta}$ \\
\hline
\end{tabular}

$* \mathrm{P}<0.05$, when compared with $\mathrm{C}$ group; ${ }^{\wedge} \mathrm{P}<0.05$, when compared with LPS group. $\mathrm{C}$, control group; LPS, lipopolysaccharide only group; L-PHC, low-dose penehyclidine hydrochloride treatment group; H-PHC, high-dose PHC treatment group.

\section{Levels of serum TNF- $\alpha$ and IL-1 $\beta$ among different groups}

A significant increase of both TNF- $\alpha$ and IL-1 $\beta$ levels in the LPS group was observed compared with the $\mathrm{C}$ group $(\mathrm{P}<0.05)$; L-PHC and H-PHC groups exhibited significant decreases of TNF- $\alpha$ and IL- $1 \beta$ levels compared with the LPS group $(\mathrm{P}<0.05)$ (Table 2).

Table 2. Changes of TNF- $\alpha$ and IL- $1 \beta$ in each group (means $\pm \mathrm{SD}, \mathrm{N}=10$ ).

\begin{tabular}{lcc}
\hline Group & TNF- $\alpha$ (ng/L) & IL-1 $\beta(\mathrm{ng} / \mathrm{L})$ \\
\hline C & $38.5 \pm 9.0$ & $46.3 \pm 12.7$ \\
LPS & $159.0 \pm 21.3^{*}$ & $130.8 \pm 18.7^{*}$ \\
L-PHC & $120.8 \pm 14.3^{\Delta}$ & $92.5 \pm 19.0^{\Delta}$ \\
H-PHC & $111.3 \pm 11.6^{\Delta}$ & $78.4 \pm 14.3^{\Delta}$ \\
\hline
\end{tabular}

$* \mathrm{P}<0.05$, when compared with $\mathrm{C}$ group; ${ }^{\Delta} \mathrm{P}<0.05$, when compared with LPS group. C, control group; LPS, lipopolysaccharide only group; L-PHC, low-dose penehyclidine hydrochloride treatment group; H-PHC, high-dose PHC treatment group.

\section{Morphological changes of renal tissue in each group}

In the LPS group, obvious edema and degeneration of tubules, glomerular capillary dilation, congestion, vasodilation, edema, and inflammatory cell infiltration in the renal interstitium were observed. However, all these damages were attenuated in both L-PHC and H-PHC groups. Images of the morphological changes are shown in Figure 1A-D. 


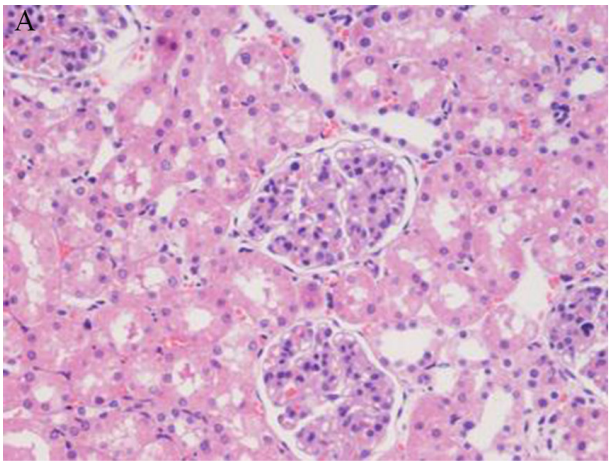

group $\mathrm{C}$

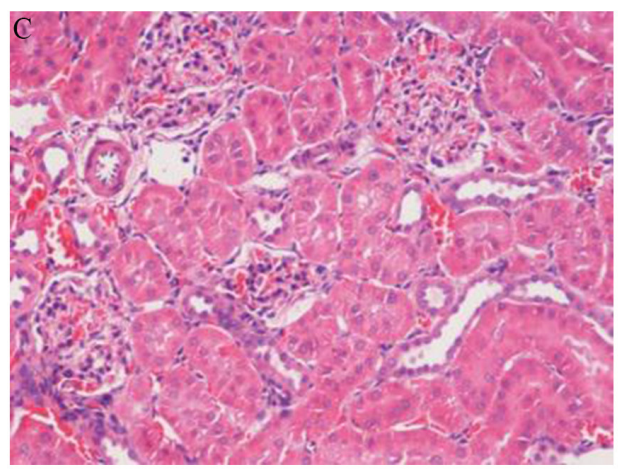

group L-PHC

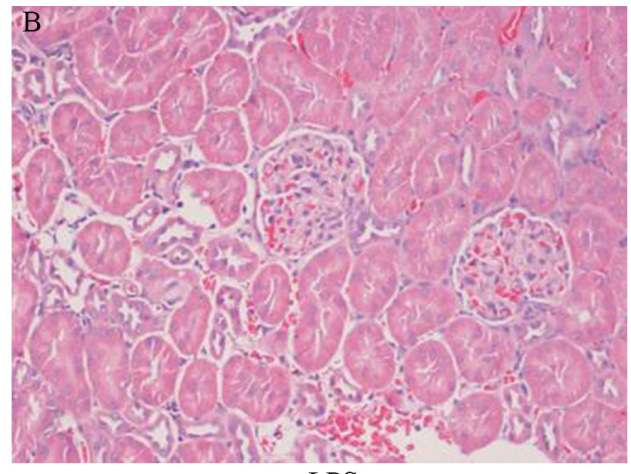

group LPS

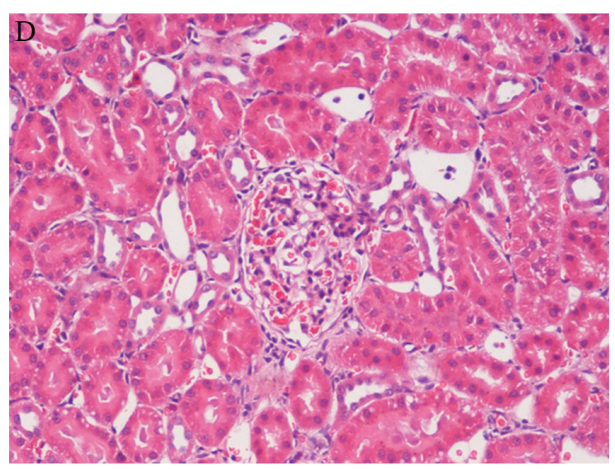

group H-PHC

Figure 1. Renal pathological histology observations. A) Control group (C); B) lipopolysaccharide only group (LPS, $5.0 \mathrm{mg} / \mathrm{kg} \mathrm{LPS}$ ); C) low-dose penehyclidine hydrochloride treatment group (L-PHC, $5.0 \mathrm{mg} / \mathrm{kg} \mathrm{LPS}+0.3 \mathrm{mg} / \mathrm{kg}$ PHC); D) high-dose PHC treatment group (H-PHC, $5.0 \mathrm{mg} / \mathrm{kg}$ LPS $+0.9 \mathrm{mg} / \mathrm{kg}$ PHC). Hematoxylin and eosinstained renal tissues from adult male Sprague-Dawley rats were observed under 200X magnification by microscopy.

In the $\mathrm{C}$ group, round nuclei and nucleoli in the proximal tubular epithelial cells could be seen distinctively, along with abundant organelles in the cytoplasm, such as ribosomes, mitochondria, rough endoplasmic reticulum, and pinocytotic vesicles. Microvilli were arranged neatly on the cell surface (Figure 2A). Furthermore, round nuclei were observed in the distal tubular epithelial cells, and abundant ribosomes, mitochondria, and pinocytotic vesicles, etc., were observed in the cytoplasm. Plasma membrane infolding and basal lamina could be seen clearly. Some short microvilli could be seen on the cell surface (Figure 2B). However, in the LPS group, there were irregular nuclei in both proximal and distal epithelial cells, with indistinct nuclear membranes. The mitochondria in the cytoplasm manifested a state of crest reducing or were vacuole-like. Microvilli could still be seen on the cell surface (Figure 2C and D). In the L-PHC group, nuclei were slightly irregular in the proximal tubular epithelial cells, while in the cytoplasm, abundant ribosomes, mitochondria, and pinocytotic vesicles could be seen, with clear plasma membrane infolding and basal lamina. Some short microvilli on the cell surface could be seen (Figure 2E). Moreover, the distal tubular epithelial cells also were rather normal with round nuclei, abundant 
organelles in the cytoplasm, and short microvilli on the surface (Figure 2F). In the H-PHC group, both proximal and distal tubular epithelial cells seemed almost healthy. The round nuclei and nucleoli in the proximal tubular epithelial cells could be seen distinctively, with abundant organelles in the cytoplasm, such as ribosomes, mitochondria, rough endoplasmic reticulum, pinocytotic vesicles, and so on. Neatly arranged microvilli could be seen on the cell surface (Figure 2G). In the distal tubular epithelial cells, there were round nuclei, abundant ribosomes, mitochondria, pinocytotic vesicles, etc. In the cytoplasm, clear plasma membrane infolding and basal lamina could be seen, and there were some short microvilli on the cell surface (Figure $2 \mathrm{H}$ ).

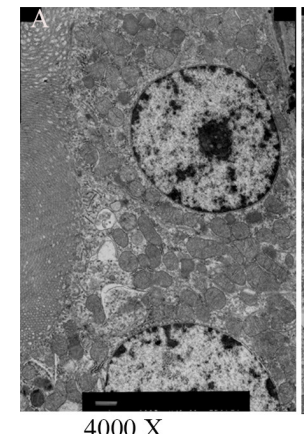

$4000 \mathrm{X}$

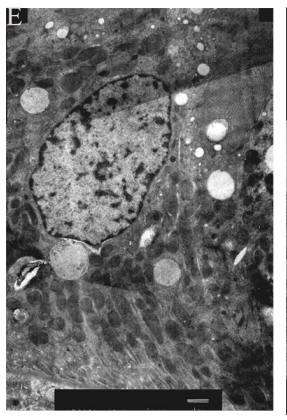

$4000 \mathrm{X}$

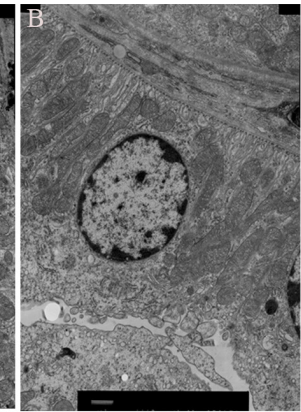

$4000 \mathrm{X}$

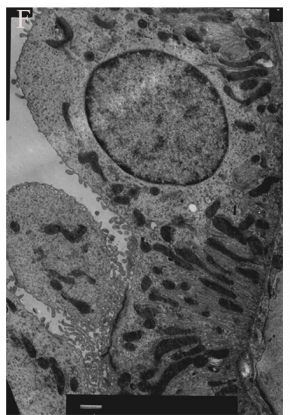

$4000 \mathrm{X}$

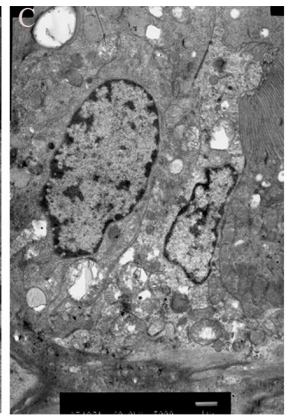

$4000 \mathrm{X}$

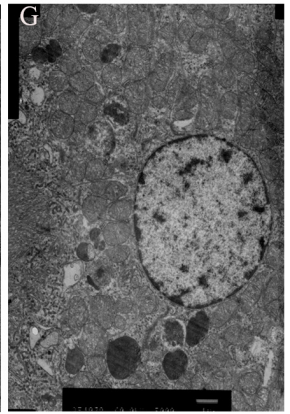

$4000 \mathrm{X}$

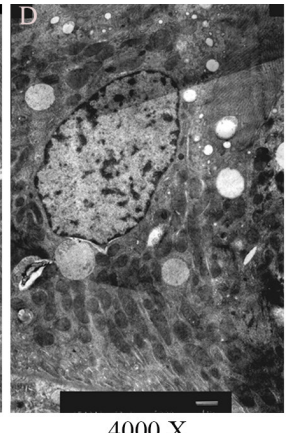

$4000 \mathrm{X}$

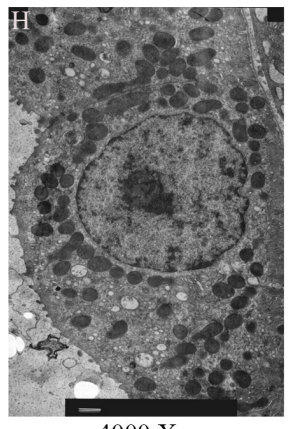

$4000 \mathrm{X}$

Figure 2. Transmission electron microscope images of rat renal tissues. A) Epithelial cells of the proximal tubules of the control group (C). B) Epithelial cells of the distal tubules of group C. C) Epithelial cell of the proximal tubules of the lipopolysaccharide only group (LPS, $5.0 \mathrm{mg} / \mathrm{kg}$ LPS). D) Epithelial cells of the distal tubules of the LPS group. E) Epithelial cells of the proximal tubules of the low-dose penehyclidine hydrochloride treatment group (L-PHC, $5.0 \mathrm{mg} / \mathrm{kg}$ LPS $+0.3 \mathrm{mg} / \mathrm{kg}$ PHC). F) Epithelial cells of the distal tubules of the L-PHC group. G) Epithelial cells of the proximal tubules of the high-dose PHC treatment group (H-PHC, $5.0 \mathrm{mg} / \mathrm{kg} \mathrm{LPS}+0.9 \mathrm{mg}$ / $\mathrm{kg}$ PHC). H) Epithelial cells of the distal tubules of the H-PHC group.

\section{Expression of tight junction proteins ZO-1 and occludin in renal tissue}

There was a significant decrease of both ZO-1 and occludin in the LPS group compared with the control group $(\mathrm{P}<0.05)$ and a significant increase of the two in both L-PHC and H-PHC groups compared with the LPS group $(\mathrm{P}<0.05)$ (Figure 3 ). 

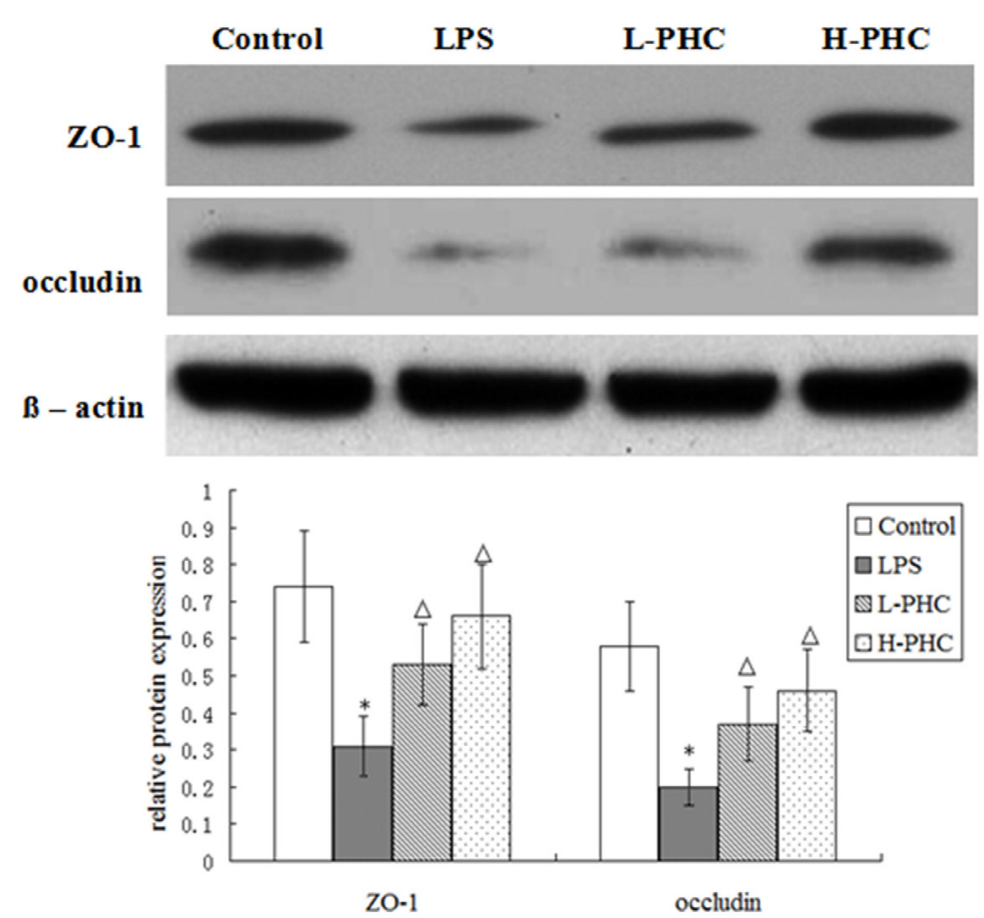

Figure 3. Expression of tight junction proteins, ZO-1 and occludin, in renal tissue. Protein bands and band density measurements in the four groups: the control group, lipopolysaccharide only group (LPS, $5.0 \mathrm{mg} / \mathrm{kg}$ LPS), lowdose penehyclidine hydrochloride treatment group (L-PHC, $5.0 \mathrm{mg} / \mathrm{kg} \mathrm{LPS}+0.3 \mathrm{mg} / \mathrm{kg}$ PHC), and high-dose PHC treatment group (H-PHC, $5.0 \mathrm{mg} / \mathrm{kg}$ LPS $+0.9 \mathrm{mg} / \mathrm{kg}$ PHC) are shown in the upper and lower panels of Figure 3 , respectively. $* \mathrm{P}<0.05$ compared with the $\mathrm{C}$ group; ${ }^{\Delta \mathrm{P}}<0.05$ compared with the LPS group.

\section{DISCUSSION}

Multiple organ system dysfunction caused by sepsis is an important cause of death in critically ill patients. Since the kidney is one of the most easily affected organs, the incidence of sepsis-induced AKI reaches about 20-35\% (Ostermann and Chang, 2007; Padilha et al., 2009). Its complex pathophysiological processes involve multiple factors, such as renal hemodynamic changes, epithelial dysfunction, parenchymal infiltration of inflammatory cells, glomerular thrombosis, tubular obstruction by necrotic cell casts or debris, and oxidative stress caused by sympathetic nervous system activation, hypovolemia, and neuroendocrine changes (Wan et al., 2008; Doi et al., 2009). Although AKI can be reversed to some extent by clinical treatment, it can still develop into chronic renal failure or end-stage renal failure. Thus, AKI not only affects the prognosis of patients with sepsis and increases the cost of hospitalization, but also increases patient mortality significantly (Chertow et al., 2005; Chvojka et al., 2010).

Sepsis caused by Gram-negative bacteria account for 50 to $60 \%$ of all sepsis cases. In these cases, lipopolysaccharide is thought to have a critical role. For instance, LPS often results in the release of various inflammatory cytokines, including IL-1, TNF- $\alpha$, IL-2, IL-6, and IL-8 (Cruz et al., 2007). Cytokines such as TNF- $\alpha$ and IL-1 $\beta$ are usually responsible for the release of radicals, nitric oxide, and eicosanoids, which then could trigger some patho- 
physiological changes in the human body. Additionally, TNF- $\alpha$ could stimulate the generation of various vasoactive mediators, induce apoptosis in renal tissue, and reduce the glomerular blood flow and glomerular filtration rate (Donnahoo et al., 2001). TNF- $\alpha$ and IL-1 $\beta$ are often considered as important mediators in the progression of sepsis. In the present study, it was well verified that LPS could increase the levels of the plasma inflammatory cytokines TNF- $\alpha$ and IL-1 $\beta$ in rats, thus inducing systemic inflammatory response.

PHC is a type of selective Belladonna drug originally made in China. In recent years, studies have focused on its inhibitory effect on the inflammatory changes in acute lung injury, such as improving microcirculation, reducing the permeability of the capillary wall, reducing lysosomal release, and suppressing the LPS-induced aggregation of polymorphonuclear leukocytes in the lung, and thus, preventing further lipid peroxidation damage (Shen et al., 2008; Li et al., 2011; Zhan et al., 2011, 2015). Results of our study also show that the application of PHC could significantly decrease the levels of Scr and BUN in the blood, which were elevated by LPS stimulation. Moreover, results of renal pathology also suggest that PHC could attenuate renal injuries caused by LPS. Our study has demonstrated the protective effect of PHC (at clinically relevant concentrations) on LPS-induced AKI.

Claudin, occludin, and ZO proteins (ZO-1, ZO-2, and ZO-3) are the tight junction proteins identified thus far. Among the three ZO proteins, ZO-1 is the most important. ZO-1 has binding sites for both occludin and claudin, and its conserved guanylate kinase, $\mathrm{SH}_{3}$, and $\mathrm{PDZ}$ domains have suggested its function of mediating the interaction between proteins that have signal transduction molecules (Furuse et al., 1993). Occludin is a tight junction protein with a molecular weight of about $60-65 \mathrm{kDa}$. It has four transmembrane domains with its carboxyland amino-terminals located in the cytoplasm and two extracellular loops crossing intercellular fissures (Furuse et al., 1993). Occludin also has multiple binding sites for serine and threonine residues, and its phosphorylation status might be related with its regulation of the cell membrane. Previous studies implied that LPS could cause renal injury and simultaneously alter the gene and protein expression of ZO-1 and occludin (Eadon et al., 2012). Further, research has suggested that in rats under extracorporeal circulation, PHC upregulates ZO-1 and occludin in the intestinal mucosa and thus, can improve the intestinal barrier (Sun et al., 2013). In the present study, there was a significant decrease of ZO-1 and occludin $24 \mathrm{~h}$ after the injection of LPS, but a subsequent injection of PHC upregulated the expression of these two tight junction proteins.

In summary, clinically relevant concentrations of PHC have certain protective effects against LPS-induced AKI. The upregulation of the tight junction proteins ZO-1 and occludin in rat renal tissue might be one of the mechanisms.

\section{Conflicts of interest}

The authors declare no conflict of interest.

\section{REFERENCES}

Bagshaw SM, Laupland KB, Doig CJ, Mortis G, et al. (2005). Prognosis for long-term survival and renal recovery in critically ill patients with severe acute renal failure: a population-based study. Crit. Care 9: R700-R709.

Bagshaw SM, Uchino S, Bellomo R, Morimatsu H, et al. (2007). Septic acute kidney injury in critically ill patients: clinical characteristics and outcomes. Clin. J. Am. Soc. Nephrol. 2: 431-439.

Chvojka J, Sy'kora R, Karvunidis T, Raděj J, et al. (2010). New developments in septic acute kidney injury. Physiol. Res. 59: 859-869.

Chertow GM, Burdick E, Honour M, Bonventre JV, et al. (2005). Acute kidney injury, mortality, length of stay, and costs 
in hospitalized patients. J. Am. Soc. Nephrol. 16: 3365-3370.

Cruz DN, Bellomo R and Ronco C (2007). Clinical effects of polymyxin B-immobilized fiber column in septic patients. Contrib. Nephrol. 156: 444-451.

Doi K, Leelahavanichkul A, Yuen PST and Star RA (2009). Animal models of sepsis and sepsis-induced kidney injury. J. Clin. Invest. 119: 2868-2878.

Donnahoo KK, Meng X, Ao L, Ayala A, et al. (2001). Differential cellular immunolocalization of renal tumour necrosis factor-alpha production during ischaemia versus endotoxaemia. Immunology 2: 53-58.

Eadon MT, Hack BK, Xu C, Ko B, et al. (2012). Endotoxemia alters tight junction gene and protein expression in the kidney. Am. J Physiol. Renal. Physiol. 303: F821-F830.

Furuse M, Hirase T, Itoh M, Nagafuchi A, et al. (1993). Occludin: a novel integral membrane protein localizing at tight junctions. J. Cell Biol. 123: 1777-1788.

Korkeila M, Ruokonen E and Takala J (2000). Costs of care, long-term prognosis and quality of life in patients requiring renal replacement therapy during intensive care. Intensive Care Med. 26: 1824-1831.

Li H, Qian Z, Li J, Han X, et al. (2011). Effects of early administration of a novel anticholinergic drug on acute respiratory distress syndrome induced by sepsis. Med. Sci. Monit. 17: BR319-325.

Metnitz PG, Krenn CG, Steltzer H, Lang T, et al. (2002). Effect of acute renal failure requiring renal replacement therapy on outcome in critically ill patients. Crit. Care Med. 30: 2051-2058

Ostermann M and Chang RW (2007). Acute kidney injury in the intensive care unit according to RIFLE. Crit. Care Med. 35: $1837-1843$

Padilha KG, Sousa RMC, Silva MCM and Rodrigues AS (2009). Patient's organ dysfunction in the Intensive Care Unit according to the Logistic Organ Dysfunction System. Rev. Esc. Enferm. USP 43: 1248-1252.

Ricci Z, Polito A, Polito A and Ronco C (2011). The implications and management of septic acute kidney injury. Nat. Rev. Nephrol. 7: 218-225.

Shen WF, Wu HH, Yang B, Gan JX, et al. (2008). PHC inhibits sequestration of neutrophils and activation of NF-kappa B in lung tissue of ALI rats induced by LPS. Chin. J. Pathophysiol. 24: 307-310.

Sun YJ, Cao HJ, Song DD, Diao, YG, et al. (2013). Probiotics can alleviate cardiopulmonary bypass-induced intestinal mucosa damage in rats. Dig. Dis. Sci. 58: 1528-36.

Uchino S, Kellum JA, Bellomo R, Doig GS, et al. (2005). Beginning and Ending Supportive Therapy for the Kidney (BEST Kidney) Investigators: Acute renal failure in critically ill patients: a multinational, multicenter study. JAMA. 294: 813-818.

Wan L, Bagshaw SM, Langenberg C, Saotome T, et al. (2008). Pathophysiology of septic acute kidney injury: What do we really know? Crit. Care Med. 36: S198-S203.

Zhan J, Liu Y, Zhang Z, Chen C, et al. (2011). Effect of penehyclidine hydrochloride on expressions of MAPK in mice with CLP-induced acute lung injury. Mol. Biol. Rep. 38: 1909-14.

Zhan J, Xiao F, Li JJ, Zhang ZZ, et al. (2015). Penehyclidine hydrochloride decreases pulmonary microvascular permeability by upregulating beta arrestins in a murine cecal ligation and puncture model. J. Surg. Res. 193: 391-398. 